IRA-International Journal of Education \&

Multidisciplinary Studies

ISSN 2455-2526; Vol.15, Issue o2 (May 2019)

Pg. no. 78-87.

Institute of Research Advances

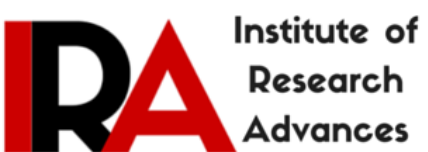

http://research-advances.org/index.php/IJEMS

\title{
Student Affairs Practitioners' Leadership on behalf of Undocumented College Students in the USA
}

Hilda Cecilia Contreras Aguirre

Texas A\&M University-Corpus Christi, United States.

Type of Work: Peer Reviewed

DOI: http://dx.doi.org/10.21013/jems.v15.n2.p4

How to cite this paper:

Aguirre, H. C. C. (2019). Student Affairs Practitioners' Leadership on behalf of Undocumented College Students in the USA. IRA International Journal of Education and Multidisciplinary Studies (ISSN 2455-2526), 15(2), 78-87.doi: http://dx.doi.org/10.21013/jems.v15.n2.p4

(C) Institute of Research Advances.

This work is licensed under a Creative Commons Attribution-Non Commercial 4.0 International License subject to a proper citation to the publication source of the work.

Disclaimer: The scholarly papers as reviewed and published by the Institute of Research Advances (IRA) are the views and opinions of their respective authors and are not the views or opinions of the IRA. The IRA disclaims of any harm or loss caused due to the published content to any party.

Institute of Research Advances is an institutional publisher member of Publishers International Linking Association Inc. (PILA-CrossRef), USA. The institute is an institutional signatory to the Budapest Open Access Initiative, Hungary advocating the open access of scientific and scholarly knowledge. The Institute is a registered content provider under Open Access Initiative Protocol for Metadata Harvesting (OAI-PMH).

The journal is indexed \& included in WorldCat Discovery Service (USA), CrossRef Metadata Search (USA), WorldCat (USA), OCLC (USA), Open J-Gate (India), EZB (Germany) Scilit (Switzerland), Airiti (China), Bielefeld Academic Search Engine (BASE) of Bielefeld University, Germany, PKP Index of Simon Fraser University, Canada. 


\section{Introduction}

The United States is considered a country of immigrants that has historically hosted people from all over the world. Oftentimes, immigrants struggle to find and shape an American identity, especially when it comes to undocumented youth (Gonzales, 2008). New waves of immigrants to this country trigger feelings of fear concerning the loss of national identity and the lack of cultural incompatibility (Kim \& Díaz, 2013a). In this sense, the emergence of anti-immigration attitudes has been in the political, social, and economic agenda over the last years. As a result, postsecondary institutions have been constantly looking for accomplishing social progress and growth (McDermott, 1973); however, there are still gaps to fill in at institutions with respect to create a welcome atmosphere and campus-wide acceptance for all students. In particular, undocumented students which the National Immigration Law Center defined as "a foreign national who: (1) entered the United States without inspection or with fraudulent documents; or (2) entered legally as a nonimmigrant but then violated the terms of his or her status and remained in the United States without authorization" (as cited in Educators for Fair Consideration, 2019) face socioeconomic and institutional barriers. Therefore, it deems necessary to find appropriate services and allocate resources that help undocumented students cope with difficulties concerning both their college adjustment and personal struggles reaching a holistic development (Gildersleeve \&Ranero, 2010). The purpose of this paper is to address the topic of undocumented students as it relates to their college persistence. In particular, four leadership theories help highlight the important role of student affairs practitioners to become advocates and seek social justice for this unique student population.

The organization of the manuscript encompasses the following sections. First, a brief literature review concerning federal and state legislation on undocumented students is presented. Then, an overview of student affairs practitioners' importance to promote a positive college climate and better serve this student population is addressed. The aforementioned section includes four leadership theories, which student affairs professionals could adopt. Next, an outline addressing the social justice aspect on behalf of undocumented students is introduced. Finally, a section covering recommendations for student affairs professionals is proposed yielding the conclusion.

\section{Background and Context}

In the 1960s, the fight against the acts of racism and discrimination faced mainly by African Americans called for a change to be treated as humans (Malcolm X, 1964). According to Malcolm X (1964), more than fighting for ones' civil rights, being recognized as human beings must be a right for every person. In this sense, people who immigrate for political, social, or financial issues often without a legal procedure becoming undocumented people are portrayed as criminals and aliens. As such, Pérez Huber (2009) noted that these concepts reinforce the negativity of having emigrated in such a situation from another country. The 1982 Plyler v. Doe U.S. Supreme Court decision provided access to K-12 education for undocumented youth, changing the lives of immigrant children who otherwise could not engage in academic and social activities (Gonzales, 2008). However, access to higher education was not granted to them mainly due to an inefficient immigration system and social negative stigmatization toward undocumented people (Teranishi, C. Suárez-Orozco \& M. Suárez-Orozco, 2015).

The frustration of much-undocumented youth who wished a college education contributed to a social movement along the past 15 years. As a result, the Development, Relief, and Education for Alien Minors (DREAM) Act has been presented several times to the House of Representatives and the Senate without success to be signed as a law (Teranishi et al., 2015). Following the era of former president Mr Barack Obama, he took executive action creating the Deferred Action for Childhood Arrivals (DACA), in which undocumented youth could temporarily study and work in the United States for two years with the possibility to renew it (Teranishi et al., 2015). Immigrants who wanted to be protected under the DACA program needed to follow rigorous requirements, such as submission of applications, background checks, and merit of amnesty for deportation (Mangan, 2017).

DACA has provided benefits to undocumented students in terms of college' and jobs' access. However, Teranishi et al. (2015) pointed out that the ambiguity and future of DACA, the vulnerability of students' families along with a hostile climate due to random deportations despite being DACA recipients (Mangan, 2017) trigger feelings of anguish and concern among undocumented college students. Approximately, between 2012 and 2016 1,653,000 undocumented youth lived in the U.S. and 497,000 were undergraduate college students (Migration Policy Institute, 2019), mostly enrolled in 2-year colleges (Teranishi et al., 2015). 
In this regard, numerous institutional agents have raised their voices addressing injustices and DACA misinterpretations, which make undocumented youth with DACA a vulnerable student population. For instance, a constitutional law professor at Harvard Law School remarked the hazardous situation DACA immigrants are living and the frightening message the current government is sending to these students (Mangan, 2017). In effect, during his campaign and once as President of the United States, Mr Donald Trump had pointed out that deportation would target criminals. Nevertheless, minor actions, such as traffic felonies or visa expirations could trigger deportation, regardless of having any kind of deferred action to be in this country (Mangan, 2017). In this regard, colleges through their respective student affairs departments, such as counselling centres and campus legal clinics are developing programs and forums to deal with students' anxiety and depression; thus, students can talk about this situation and even getting help through advising (GrayCox, 2017). Due to the hostile environment happening in colleges and universities nationwide, Gray Cox (2017) argues that postsecondary education institutions should seek options that guarantee to protect the basic rights of undocumented students and promote their academic development regardless of their immigrant status. In this sense, colleges with campus abroad could be a possibility for students being threatened with immediate deportation; thus, they could enrol in a study abroad program and be protected as college students (Gray Cox, 2017).

In particular, the California college system through its institutional authorities, faculty, and students has shown strong advocacy in supporting undocumented students by pledging protective measures for undocumented students. However, some of these colleges that are openly protecting undocumented students fear the cut of funding by not complying to state and federal laws (Najmabadi, 2016). Many college vice presidents of student affairs departments are currently taking actions to support undocumented students and raise awareness throughout the campus by promoting panels and talks; hence, recipients of DACA do not feel alone and isolated (Field, 2017). Further, taking into account the problematic situation of undocumented college students, university presidents and academic leaders should find strategies that help support this vulnerable student population (Gray Cox, 2017). For example, Pomona College already supports undocumented students through financial aid and supportive services. The University of California at Los Angeles calls for enhancing the counselling services for students with immigration issues (Gordon, 2015), as well as developing programs in which undocumented students' families receive support and advice (Najmabadi, 2016).

In addition, undocumented students, regardless if they are under DACA protection, fear their deportation and even more the deportation of family and friends (Teranishi et al., 2015). In some cases, family members' residency status in the U.S. is illegal and they could be deported at any time (Field, 2017; Gordon, 2015). Yet, universities are developing networks among students to support with funds other students with immigration issues or act as legal observers during protests (Field, 2017). Because often undocumented college students are not eligible for student loans and grants in several states, these students are less likely to attain a college degree; frequently, they are part-time students, and, consequently, it takes longer to graduate (Bjorklund, 2018). Usually, undocumented students study in colleges that are nearby home; hence, they avoid additional expenses (Gonzales, 2008). Even when California and a few more states have achieved that undocumented students benefit from in-state tuition and grants; nationwide, postsecondary institutions consider this student population as highly vulnerable and stigmatized(Gordon, 2015).

\section{Federal and State Legislation}

The controversial situation of undocumented college students in institutions of higher education can be analyzed through two different lenses. At a federal level, the first legislation granting access to higher education for undocumented students but rejecting the opportunity to benefit from federal loans and grants was the Higher Education Act of 1965 (Kim \& Díaz, 2013b). By 1996, under the Bill Clinton administration two acts were enacted: The Illegal Immigration Reform and Immigrant Responsibility Act (IIRIRA) and the Personal Responsibility and Work Opportunity Reconciliation Act (PRWORA). Although these two legislations do not state explicitly the rejection of financial aid for undocumented students, their ambiguous meaning has allowed states to interpret these acts as a ban on enrolling undocumented students and granted the benefits of in-state tuition (Kim \& Díaz, 2013b).

In 2001, the Development, Relief, and Education for Alien Minors (DREAM) was introduced by federal legislators in which undocumented students had the possibility to be considered legal college students and even achieving legal residency. Unfortunately, neither this bill nor other versions have passed. By executive order, the Obama administration passed a law titled Deferred Action for Childhood Arrival's Program (DACA) by which 
immigrants could attend colleges but without the benefit to become permanent residents (Kim \& Díaz, 2013b). The inconsistency of federal laws among states has provoked wide variability of contexts in which students operate (Valenzuela, Pérez, Pérez, Montiel, \& Chaparro, 2015). In 2017, the Trump administration repealed DACA; nevertheless, "in early 2018, federal judges in California, New York, and Washington, D.C. ruled against the administration's repeal, leaving the law's future uncertain" (Bjorklund, 2018, p. 636). Hoping that the bipartisan legislation signs a bill that protects undocumented youth, it is still unforeseeable what the future will look like for undocumented college students (Bjorklund, 2018).

At a state level, 12 states have passed legislation that allows undocumented students to have access to postsecondary education with in-state tuition rates (Jefferies, 2008; Kim \& Díaz, 2013b). For instance, in 2001, the state of Texas signed a law in which undocumented students could have access to in-state tuition; however, other states, such as Arizona, Alabama, and Georgia have passed policies restringing undocumented students' eligibility (Bjorklund, 2018; Cebulko \& Silver, 2016; Flores 2010). In this regard, Kim and Díaz (2013b) highlighted that states adopting in-state tuition fees have witnessed a considerable increase in undocumented students' enrollment. Namely, if undocumented students countrywide could have access to higher education with the benefits of both instate tuition and financial aid, it would be more likely that undocumented students attend college, attain a college degree, and have access to better jobs (Kim \& Díaz, 2013b).

\section{Overview of Student Affairs Practitioners' Leadership}

John Dewey argued that educational institutions should be places where social progress is promoted by everyone involved in education (McDermott, 1973). In this sense, fostering a welcoming campus atmosphere is one of the most important aspects of the college persistence of undocumented students. Equally, comprehensive and informed administrators, faculty, and staff are an essential factor in such campus climate (Bjorklund, 2018). In particular, counsellors, mentors, and faculty in their role of academic and professional advisors should be conscious about undocumented students' challenges and take appropriate actions (Gildersleeve\&Ranero, 2010). In addition, Pérez (2010) suggested roles that can be taken by student affairs professionals, such as student organizations' advisors or fundraising committee coordinators on behalf of undocumented students.

Due to their residency status in this country, undocumented students are a vulnerable student population and at high risk of dropping out of college (Gonzales, 2008). Thus, communication and empathy are at the core of a student-mentor, counsellor, or adviser relationship, which must be based on mutual collaboration, communication, trust, and genuine care and love (Freire, 2000; Tschannen-Moran, 2013). The leadership adopted by student affairs professionals will influence deeply undocumented students to accomplish activities, tasks, and projects (Gardner, 2013; Northouse, 2013) as it relates to generating academic and social capital. A critical aspect to be considered is that most undocumented students are first-generation students and may need additional information to navigate the college experience (Pérez Huber, 2009). Consequently, the analysis of student affairs practitioners' contributions to undocumented students' academic success is addressed through four leadership styles: (1) Path-Goal Theory, (2) Leader-Member Exchange Theory, (3) Authentic Leadership, and (4) Adaptive Leadership.

\section{(1) Path-Goal Theory}

The path-goal theory defines specific characteristics of leaders and followers. Substantial "needs of affiliation" (Northouse, 2013, p. 119) seems essential for followers who seek approachable leaders who support them. Because path-goal theory focuses on the influence of leaders on followers, trust is a core feature of any human relationship. In this sense, leaders who have been able to develop a high-trust culture will encounter the need for less rigid rules and procedures to accomplish tasks from followers. In a university environment, where communication and trust have been cultivated, leaders are more likely to find high levels of cooperation and commitment (Tschannen-Moran, 2013). As such, student affairs professionals could react as follows:

Finding followers' motivation. Usually, undocumented students who enrol in postsecondary institutions are highly motivated to have the opportunity to be college students but unsatisfied of their residency status. Thus, in order to improve their performance in college, student affairs professionals need to establish a path by which students reach their goals. Oftentimes, undocumented students are also first-generation students; thus, the option to be college students is highly influenced by universities' features, including better financial aid, closeness to their parents' home, and flexibility in classes' schedule to be able to work (Valenzuela et al., 2015). Likewise, undocumented students could eventually need to feel psychological support and explicitly, follow directions; in this 
case, directive leadership will provide students with straightforward indications of tasks' performance as well as expectations to be met (House \& Mitchell, 1975). This follower's characteristics describe the need of supportive leadership as a means to cope with students' difficulties and anxiety provoked by the uncertain future and sometimes, the lack of support from their families (House \& Mitchell, 1975; Valenzuela et al., 2015). A genuine interconnection between students and staff is needed to help achieve enriching and meaningful exchanges, the next theory addresses this topic.

\section{(2) Leader-Member Exchange Theory}

Graen and Uhl-Bien (1991) used the term leadership making to examine the roles, influences, exchanges, and interest between leaders and followers over a timeline. The relationship between leaders and followers might go through three phases: (1) The stranger phase where the interactions are formal and structured. (2) The acquaintance phase is a transitionary and uncertain phase in which there is more influx of information. This phase could be of discovery for both parties. And 3) the partnership phase is described as the phase where high-quality exchanges happen in a leader-follower relationship (Graen \& Uhl-Bien, 1991). In this sense, Graen and Uhl-Bien (1995) underlined the quality of the leadership based on the interactive role of all three: leader, follower and the relationship. Based on this theory, student affairs practitioners could adopt the following approach:

Seeking high-quality exchanges. Undocumented students are a heterogeneous group because each student comes from different ethnic, cultural, and educational backgrounds (Hernandez, Hernandez, Gadson, Huftalin, Ortiz, White, \& Yocum-Gaffney, 2010). Oftentimes, their educational experiences and home environment might be distinct from other students.

According to Hernandez et al. (2010), usually undocumented students do not disclose sensitive information to anybody but with whom they believe they can trust. In effect, finding allies can be a tough process for undocumented students because not all people may show sympathy for their situation (Valenzuela et al., 2015). Hence, students' affairs practitioners should look for efficient strategies that help them identify undocumented students and understand their struggles. Undocumented students could experience the phases found by Graen and Uhl-Bien (1991) as follow: In the first phase, undocumented students might perceive staff and faculty as professionals who perform their job without any personal tie to students; thus, they share their private information only to their closest friends. The second phase could be of mutual discovery; on the one hand, the professional could find out the immigrant status of a student but not discuss it. On the other hand, the undocumented student could start revealing more personal information to the professionals and perceive that they are people of trust. Finally, the third phase describes the stage where high-quality exchanges happen in a leader-follower relationship. In addition, undocumented students and student affairs professionals might be able to fully trust each other. Consequently, student affairs practitioners must be careful and avoid venting students' immigrant status, issues they have experienced on and off campus, and current and future concerns as well (Graen \& Uhl-Bien,1991). Being rightful and acting on behalf of undocumented students' well-being allows showing students what authentic leaders do, as addressed in the following theory.

\section{(3) Authentic Leadership}

According to Northouse (2015), authentic leadership is a new theory with high possibilities of further development. This theory focuses on the leader's authenticity and its influence on the leader-follower relationship (Northouse, 2015). In turn, Hackman and Johnson (2013) catalogued leader's authenticity as one of the virtue ethics of leaders because it helps followers "find meaning in work, foster optimism, build trust and commitment levels and promote an ethical climate" (p. 355). In other words, the behaviour and thinking of leaders align with their acts generating a positive climate for followers' performance. In this regard, George (2003) proposed five essential elements leaders must have to achieve a veritable relationship as follow: (1) purpose,(2) values,(3) relationships,(4) self-discipline, and (5) heart. As such, leaders use their core values to lead others. Student affairs professionals could apply the aforementioned aspects as explained next:

Contributing as facilitators. In college, student affairs professionals should help undocumented students in developing the aforementioned five dimensions as follows: 1) Student affairs professionals should help undocumented students define a congruent and reachable purpose; inner motivation and a sense that a set of goals is reachable should be part of it. Despite undocumented students face adverse situations on a daily basis, George (2003) noted that individuals should have a profound interest and care about their daily activities. 2) Student affairs 
practitioners must be aware of undocumented students' situation and help them find their identity, direction, and values. Thus, they can surpass difficulties with a clear sense of how to behave and react. 3) Student affairs professionals should contribute to students' ability to build relationships. This is certainly one of the most difficult for undocumented students because students experience feelings of fear, insecurity, and uncertainty when strangers or unknown find out their immigrant status (George, 2003). Students looking for authenticity need first, to discover receptiveness and second, empathy in other people to build a relationship (Hernandez et al., 2010). 4) Student affairs professionals should create a supportive environment campus-wide by informing students about their responsibilities and rights as students (Hernandez et al., 2010). This is an opportunity for undocumented students to know about the requirement and responsibilities as a college student. Certainly, the authentic leader possesses energy and vitality to achieve their goals according to a set of values (George, 2003). In other words, it is through self-discipline that undocumented students could accomplish their goals and complete a college degree. 5) Finally, because undocumented students cannot have a legal job, they usually look for giving back to their community by using different approaches (Hernandez et al., 2010). In this sense, the compassion that students feel for others within their community by sharing their experiences, participating in community service activities, or being members of other ethnic groups is of the utmost importance when it comes to behaving like an authentic leader (George, 2003).

Working on becoming an authentic leader is a process, which should be complemented with adaptive leadership skills. Such abilities might help students dealing with changes and adjustment, the next theory covers this subject.

\section{(4) Adaptive Leadership}

Adaptive leadership addresses the motivation leaders provide to followers who need to deal with challenging situations, sudden changes, and adjustment processes (Northouse, 2015). The model developed by Heifetz (1994) provided three different perspectives as follows: situational challenges, leader behaviours, and adaptive work. Helping followers in situational challenges implies to re-learn core values, such as perceptions, beliefs, and attitudes. As followers adopt, leaders should be able to give directions and provide protection and orientation at difficult moments. Finding a safe environment due to effective communication means that adaptive work has succeeded (Heifetz, 1994; Heifetz, Grashow, \& Linsky, 2009; Heifetz \& Laurie, 1997).

Adopting changes. In order to help undocumented students adapt for college, student affairs professionals in their role as leaders are accountable for nurturing an environment to inform other individuals of undocumented students' situation. Communicating with people about undocumented students' challenges in life and college can help shift people's mindset and generate a culture of mutual learning and development (Heifetz, 1994). Consistently, the behaviour of leaders is crucial for achieving followers' identification. The ability to move away of a challenging situation can be key to successfully find a solution; thus, student affairs professionals need to be able to identify undocumented students' challenges and contribute to finding alternatives to help them succeed academically. Furthermore, because being college students is by itself challenging, undocumented students have multiple and diverse challenges. One of them is to adapt to the university climate and this represents learning how to navigate the college experience, meeting the demanding requirements of courses, participating in campus clubs or organizations, being accountable as students, and even, performing a job off campus. In this sense, student affairs professionals need to smooth that transition period while providing direction and information (Heifetz \& Laurie, 1997). Additionally, it is of utmost importance that student affairs professionals promote that other university staff helps immigrant students be disciplined as college students, face their reality, and provide helpful information as well as academic support to foster students' holistic development (Heifetz \& Laurie, 1997).

Additionally, student affairs professionals must acknowledge that even when they are in a position of directing students, undocumented students as other students should be autonomous and independent individuals in making decisions and managing their resources. The aforementioned information includes knowing the consequences of dropping a class, working full-time shift while a full-time student or considering changing their major. Empowering student is an effective strategy that student affairs professionals could use if they want undocumented students to succeed.

Overall, the work of student affairs practitioners should be effective in designing an adequate college environment where students, faculty, and staff are informed about undocumented students' issues and their reality (Phi Theta Kappa, 2006). Additionally, in fostering the participation and involvement of anti-immigrant individuals on campus' talks and debates related to immigration can help increase acceptance and sympathy for undocumented 
immigrant students and their families as well (Phi Theta Kappa, 2006). More importantly, undocumented students might have the opportunity to develop fully their capacities as human beings in socializing with other individuals and as students in acquiring the knowledge and skills that later can be applied in a job (Heifetz, 1994).

\section{Limitation}

Even when the aforementioned theories could be employed to improve how postsecondary institutions serve vulnerable students such as undocumented students, the fact that all theories were developed by and for White males conflicts with the intention to help undocumented students in oppressive environments. In this sense, Pérez Huber (2009) highlighted the history of racism that minorities such as Latinos face in the United States. A country whose White people considered themselves the natives (Pérez Huber, 2009) and frame "racial stereotypes, prejudices, ideologies, images, interpretations and narratives, emotions, and reactions to language accents, as well as racialized inclinations to discriminate" (Feagin, 2013, p. 3). As such, with a White worldview perspective is difficult to imagine what minorities face in their attempt to succeed.

For the most part, undocumented students experience feelings of shame due to their illegal status and discrimination of different kinds, especially from the media, which portrays negative attitudes against these vulnerable individuals (Pérez, 2010; Vélez, Huber, Lopez, De La Luz, \& Solórzano, 2008). Even facing hate acts through micro-aggressions from people who stereotype undocumented students as inferior (Pérez, 2010). In addition, Stebleton (2015) noticed that undocumented students usually trust in institutional agents who share their race, language, or cultural background creating a special bond. When those student affairs professionals do not have any commonality, it is less likely that they achieve a true connection. Hence, the importance of acquiring the information and skills to better serve undocumented students, regardless of student affairs practitioners' racial, linguistic, and cultural features.

\section{Social Justice on behalf of Undocumented Students}

From a social justice perspective, this section examines notions of equity and liberation, then positioning student affairs professionals as advocates and agents of change for undocumented students. To begin with, Bankston (2010) addressed social justice as the equitable distribution of resources among all people as a fundamental right. However, scientists have criticized the original idea of equity for all, arguing that having social justice is much more complex than the fair allocation of resources (Atweh, 2011). In addition, there is a tendency to use labels to classify people, usually by race, gender, and class. This classification is itself discriminatory because our society tends to favour rich and White males over minorities (Bankston, 2010).

In this sense, Freire (2000) highlighted that having vertical relationships allows that the underrepresented, disadvantage, and poor become the oppressed in society. Thus, the oppressors are the ones with power and authority to manipulate the uneducated, ignorant, and alienated. The vicious circle generated by these human exchanges are more likely to end if the oppressed learn to discover the potential of self-awareness, develop critical consciousness, and find as well as define their identity Freire (2000). All three aspects are of critical importance for undocumented students who have lived most of their lives in oppressive environments at home, in school, and at work. The society at large, as oppressors, criticizes the right of undocumented students to be in college and have access to in-state tuition and financial aid. In this sense, McArthur (2010) pointed out the close relationship between society and education and how society influences education; thus, to improve social justice a change must occur in society to successfully foster critical pedagogy.

Critical pedagogy entails an open dialogue among humans; thus, ideas and opinions flow harmoniously. According to Freire (2000) to find liberation, the oppressed and oppressor need to communicate and this communication requires including love and care to be authentic dialogue. Still, Bankston (2010) considered people as actors who are agents of change regardless of their living conditions. Aligned with the aforementioned information is the banking concept of Freire (2000) who argued that students are not passive learners but powerful and creative human beings who must interact and open a dialogue with colleagues and instructors altogether. Consistently, undocumented college students in their continuous search for genuine identity are required to speak out their opinions, fears, and troublesome experiences that have faced in the only country they probably know. However, society constantly looks for diminishing their value as human beings by taking away opportunities to be educated, improve their quality of life, and aspire a better life for future generations (Jefferies, 2008). 
Indeed, advocates of undocumented immigrant students highlight the importance of a meritocratic ideology by which society accepts and integrates this vulnerable population by considering individual features, including work integrity, values, and talents. This approach provides hope and motivation for young immigrants to look for spaces and places where they can succeed (Jefferies, 2008). In this sense, student affairs professionals must foster hope and support in the academic context; thus, undocumented students can use their talents and knowledge (Gildersleeve \&Ranero, 2010; Pérez, 2010). A university climate in which undocumented students as well as other under-represented student populations interact with faculty and staff in a respectful, honest, trustful, and positive manner would help develop a sense of belonging and commitment. In effect, all stakeholders should be involved to develop students holistically (Gildersleeve \&Ranero, 2010). Additionally, student affairs practitioners should consider strategies to promote social justice across the campus, by which every individual has the opportunity to learn, participate, interact, comment, suggest, argue, and motivate others to become a better version of themselves. Therefore, the university's climate promotes inclusion and equity (Gildersleeve \&Ranero, 2010).

\section{Recommendations and Conclusion}

This section provides recommendations for student affairs practitioners in adopting some of the aforementioned leadership theories to improve the personal and academic experiences of undocumented college students. A final reflection follows this section.

First, the path-goal theory, which mainly focuses on leaders help; thus, followers can accomplish their goals. In using this approach, student affairs practitioners should first identify and define personal and professional goals and consequently, develop a set of values, such as kindness, service, balance, and positive attitude to better serve these students (Sanft, Jensen, \& McMurray, 2008). Having clear expectations of oneself and enhancing one's value system would be a useful strategy to help others to find manners to improve their performance and motivation. In effect, to be role models, student affairs professionals need to authentically find who they are as individuals and how they can help others. Likewise, student affairs offices should collaborate with other academic departments and faculty on behalf of students' success (Cho \& Sriram, 2016). Moreover, the institution's size and type, individual experiences, and educational background along with institutional resources and academic programs define the kinds of support college students can have access(Roberts, 2005).In other words, the potential of consciously aligning behaviours and competencies would eventually influence others to consistently think and act with a clear purpose in mind.

The path-goal theory risks creating a dependency between followers and leaders. Therefore, student affairs professionals should be aware of developing in undocumented students a mindset in which students learn about decision-making, facing acts and behaviours, as well as dealing with challenging situations. In college, students make important decisions that influence their lives in the short and long term; hence, the importance of developing in students a sense of making informed decisions and becoming independent and critical thinkers.

Second, the leader-member exchange theory is based on the interaction process between leaders and followers. In particular, this theory points out the importance of the leader-follower relationship. Such an approach contributes to the understanding of how the leader-follower relationship matures over time, that is, as the relationships grow, there is a buildup of trust between leader and follower. In this sense, student affairs professionals as leaders should develop their human capacities and professional's ability to be sympathetic and show trust with students they interact with on a daily basis.

Understanding students' diversity, and, consequently, their differences, from both an individual perspective and an organizational culture lens (Cho \& Sriram, 2016), including struggles, concerns, fears, challenges, and difficulties would help student affairs practitioners meet more appropriately students' academic and personal needs. The aforementioned is especially important when it comes to undocumented college students who have suffered because of discrimination and judged by society. In this sense, student affairs professionals must consider appropriate strategies to empower students that help them break with negative perceptions and actions. The importance of helping undocumented students lies in their vulnerability as citizens and college students because society stereotypes them as intruders and opportunists (Pérez, 2010).

Finally, the authentic leadership theory, which addresses the authenticity of leaders and the way they lead others. Usually, in this type of leadership, leaders influence others through their core values and convincingly, leaders lead with honesty and passion (Northouse, 2015). In the process of becoming authentic leaders, student 
affairs professionals should integrate a sense of social awareness in which they fully understand other points of view, listen to others' opinions, and establish two-way communication patterns (Nelson \& Low, 2003). In choosing this approach, student affairs practitioners can develop effective interpersonal relationships with a broad range of individuals.

Student affairs professionals using authentic leadership should genuinely seek the academic success of undocumented students, show care for their emotional well-being, and especially, help them when they are struggling either socially or academically. Furthermore, it is imperative for student affairs practitioners to develop their listening skills; thus, students feel heard and valued as someone is paying attention to them (Zaniewski \& Reinholz 2016). Consistently, undocumented students will feel confident and ease as the relationship between staff and students strengthen in a genuine way.

In general, the increasing waves of immigrants moving around the world, especially from developing countries to developed nations prevail. The United States, as a receptor of thousands of immigrants, through its colleges and universities, requires to be cognizant of how meeting the academic and social needs of undocumented immigrant college students from a social justice lens. Essentially, by implementing appropriate policies and practices, institutions of higher education can promote a postsecondary climate in which individuals regardless their background should have the opportunity to move forward, improve their quality of life, and succeed in life. As Freire (2000) stated, the only way to liberate the oppressed is through true dialogue; hence, they can be aware of their inner strength and their full capacities as human beings.

\section{References}

[1]. Atweh, B. B. (2011). Reflections on social justice, race, ethnicity, and identity from an ethical perspective. Cultural Studies of Science Education, 6(1), 33-47.

[2]. Bankston, C. L. (2010). Social justice: Cultural origins of a perspective and a theory. The Independent Review, 15(2), 165-178.

[3]. Bjorklund, P., Jr. (2018). Undocumented Students in Higher Education: A Review of the Literature, 2001 to 2016. Review of Educational Research, 88(5), 631-670.

[4]. Cebulko, K., \& Silver, A. (2016). Navigating DACA inhospitable and hostile states: State responses and access to membership in the wake of Deferred Action for Childhood Arrivals. American Behavioral Scientist, 60, 1553-1574.

[5]. Cho, A. R., \& Sriram, R. (2016). Student affairs collaborating with academic affairs: Perceptions of individual competency and institutional culture. College Student Affairs Journal, 34(1), 56-69.

[6]. Educators for Fair Consideration. (2019). An overview of college-bound undocumented students. Retrieve from https://my.academyart.edu/content/dam/assets/pdf/undoc_stud_overview.pdf

[7]. Feagin, J. R. (2013). The white racial frame: Centuries of racial framing and counter-framing. New York, NT: Routledge.

[8]. Field, K. (2017, February 24). Colleges try to ease immigrant students' stress as the government steps up deportations. The Chronicle of Higher Education. Retrieved from http://www.chronicle.com/article/Colleges-Try-to-EaseImmigrant/239317

[9]. Flores, S. M. (2010). The first state dream act: In-state resident tuition and immigration in Texas. Educational Evaluation and Policy Analysis, 32, 435-455.

[10]. Freire, P. (2000). Pedagogy of the oppressed (30th ed). London, ENG: Bloomsbury Academic.

[11]. Gardner, J. W. (2013). The nature of leadership. In Grogan, M. (Ed.), Educational Leadership (3rd ed) (pp. 17-27). San Francisco, CA: Jossey-Bass.

[12]. George, B. (2003). Authentic leadership: Rediscovering the secrets to creating lasting value. San Francisco, CA: Jossey-Bass.

[13]. Gildersleeve, R. E., \&Ranero, J. J. (2010). Precollege contexts of undocumented students: Implications for student affairs professionals. New Directions for Student Services, 2010(131), 19-33.

[14]. Gonzales, R. G. (2008). Left out but not shut down: Political activism and the undocumented student movement. $N w$. $J L \&$ Soc. Pol'y, 3, 219-239.

[15]. Gordon, L. (2015). Migrant college students face more stress than their peers, study says. Los Angeles Time. Retrieved from http://www.latimes.com/local/education/la-me-ucla-study-20150127-story.html

[16]. Graen, G. B., \& Uhl-Bien, M. (1991). The transformation of professionals into self-managing and partially selfdesigning contributors: Toward a theory of leadership-making. Management Department Faculty Publications, 16, 2539.

[17]. Graen, G. B., \& Uhl-Bien, M. (1995). Relationship-based approach to leadership: Development of leader-member exchange (LMX) theory of leadership over 25 years: Applying a multi-level multi-domain perspective. The Leadership Quarterly, 6(2), 219-247. 
[18]. Gray Cox, J. (2017, February 28). To protect undocumented students, prepare for study-abroad option. Chronicle of Higher Education. Retrieved from http://www.chronicle.com/blogs/letters/to-protect-undocumented-students-preparefor-study-abroad-option/

[19]. Hackman, M. Z., \& Johnson, C. E. (2013). Leadership: A communication perspective. Long Grove, IL: Waveland Press.

[20]. Heifetz, R. A. (1994). Leadership without easy answers. Cambridge, MA: Belknap Press.

[21]. Heifetz, R. A., Grashow, A., \& Linsky, M. (2009). The practice of adaptive leadership: Tools and tactics for changing your organization and the world. Harvard Business Press.

[22]. Heifetz, R. A., \& Laurie, D. L. (1997). The work of leadership. Harvard Business Review, 7(1), 124-134.

[23]. Hernandez, S., Hernandez, I. J. Gadson, R., Huftalin, D., Ortiz, A. M., White, M. C., \& Yocum-Gaffney, D. (2010). Sharing their secrets: Undocumented students' personal stories of fear, drive, and survival. New Directions for Student Services, (131), 67-84.

[24]. House, R. J., \& Mitchell, T. R. (1975). Path-goal theory of leadership. (No. TR-75-67). Washington University Seattle Department of Psychology.

[25]. Jefferies, J. (2008). Do undocumented students "play by the rules"? Journal of Adolescent \& Adult Literacy, 52(3), 249-251.

[26]. Kim, E., \& Díaz., J. (2013a). Theoretical Foundation: Immigrant Student College Transition and Persistence. ASHE Higher Education Report, 38(6), 25-46.

[27]. Kim, E., \& Díaz., J. (2013b). Undocumented students and higher education. ASHE Higher Education Report, 38(6), 7790.

[28]. Malcolm, X. (1964). The ballot or the bullet. April, 3, 23-44.

[29]. Mangan, K. (2017, February 16). Undocumented students' fears escalate after a DACA recipient's arrest. The Chronicle of Higher Education. Retrieved from http://www.chronicle.com/article/Undocumented-StudentsFears/239214

[30]. McArthur, J. (2010). Achieving social justice within and through higher education: The challenge for critical pedagogy. Teaching in Higher Education, 15(5), 493-504.

[31]. McDermott, J. J. (1973). The Philosophy of John Dewey. The University of Chicago Press.

[32]. Migration Policy Institute. (2019). Profile of the unauthorized population: United States. Retrieve from https://www.migrationpolicy.org/data/unauthorized-immigrant-population/state/US

[33]. Najmabadi, S. (2016, December 02). How colleges are responding to demands that they become 'sanctuary campuses.' The Chronicle of Higher Education. Retrieved from http://www.chronicle.com/article/How-Colleges-Are-Respondingto/238553

[34]. Nelson, D. B., \& Low Gary. R. (2003). Emotional intelligence: Achieving academic and career excellence. Upper Saddle River, NJ: Pearson Education.

[35]. Northouse, P. G. (2015). Leadership: Theory and practice (7th ed). San Francisco, CA: Sage.

[36]. Pérez Huber, L. (2009). Challenging racist nativist framing: Acknowledging the community cultural wealth of undocumented Chicana college students to reframe the immigration debate. Harvard Educational Review, 79(4), 704730.

[37]. Pérez, W. (2010). Higher Education Access for Undocumented Students: Recommendations for Counseling Professionals. Journal of College Admission, 206, 32-35.

[38]. Phi Theta Kappa. (2006). Leadership development studies: A humanity approach (4 ${ }^{\text {th }}$ ed). Jackson, MS: Phi Theta Kappa, Inc.

[39]. Roberts, D. M. (2005). Skill development among student affairs professionals. College Student Affairs Journal, 24(2), 170-179.

[40]. Sanft, M., Jensen, M., \& McMurray, E. (2008). Peer mentor companion. Belmont, CA: Waldsworth.

[41]. Stebleton, M. J., \&Aleixo, M. B. (2015). Examining undocumented Latino/a student interactions with faculty and institutional agents. Journal of Hispanic Higher Education, 14(3), 256-273.

[42]. Teranishi, R. T., Suárez-Orozco, C., \& Suárez-Orozco, M. (2015). In the shadows of the ivory tower: Undocumented undergraduates and the liminal state of immigration reform. The Institute for Immigration, Globalization, \& Education. University of California, Los Angeles.

[43]. Tschannen-Moran, M. (2013). Becoming a trustworthy leader. In Grogan, M. (Ed.), Educational Leadership (3rd ed) (pp. 40-54). San Francisco, CA: Jossey-Bass.

[44]. Valenzuela, J. I., Pérez, W., Pérez, I., Montiel, G. I., \& Chaparro, G. (2015). Undocumented students at the community college: Creating institutional capacity. New Directions for Community Colleges, 172, 87-96.

[45]. Vélez, V., Huber, L. P., Lopez, C. B., De La Luz, A., \& Solórzano, D. G. (2008). Battling for human rights and social justice: A Latina/o critical race media analysis of Latina/o student youth activism in the wake of 2006 anti-immigrant sentiment. Social Justice, 35(1 (111), 7-27.

[46]. Zaniewski, A. M. \& Reinholz D. (2016). Increasing STEM success: A near-peer mentoring program in the physical sciences. International Journal of STEM Education, 3(14), 1-12. doi: 10.1186/s40594-016-0043-2 